(c) 2020, The Authors. Published by FASS Inc. and Elsevier Inc. on behalf of the American Dairy Science Association ${ }^{\circledR}$. This is an open access article under the CC BY-NC-ND license (http://creativecommons.org/licenses/by-nc-nd/4.0/).

\title{
Short communication: Hypernatremia in diarrheic calves associated with oral electrolyte administration in water and milk replacer in absence of access to water
}

\author{
Juliette N. Wilms, ${ }^{*}$ (1) Leonel N. Leal, $\odot$ and Javier Martín-Tereso $\odot$ \\ Trouw Nutrition R\&D, PO Box 299, 3800 AG, Amersfoort, the Netherlands
}

\section{ABSTRACT}

A major goal in treatment of calves with diarrhea is to restore hydration and to correct metabolic acidosis. This can be achieved by the administration of oral electrolyte solutions (OES). However, the composition of OES products and the administration protocols in practice vary widely, which can potentially compromise the efficacy and safety of these treatments. In particular, administration of OES in milk replacer (MR) and the absence of water supply in young calves are not unusual and these conditions could compromise calf health. In this light, the objective of this study was to evaluate the efficacy and safety of OES administered in MR and in water without access to water. Forty-five male Holstein calves $(16.6 \pm 1.6 \mathrm{~d}$ of age and $45.4 \pm 2.2 \mathrm{~kg}$ at arrival) were purchased from a collection center located in the Netherlands. After arrival, calves went through an adaptation period of $4 \mathrm{~d}$. Calves that developed diarrhea within $6 \mathrm{~d}$ after the end of the adaptation period were enrolled in the study, and the remaining calves were sold after being weaned. Upon morning detection of abnormal fecal scores (d 1 starting point), calves were blocked based on initial BW. Within each block, calves were randomly assigned to 1 of 2 treatments, including a control consisting of a small dose of whey $(\mathrm{CON} ; \mathrm{n}=12)$ and an OES treatment $(\mathrm{OES} ; \mathrm{n}=14)$. Treatments were blinded to the farm staff by randomly assigning a letter to each treatment. Treatments were simultaneously administered for $4 \mathrm{~d}$ in $\mathrm{MR}(2.5 \mathrm{~L}$ at 0800 and $1730 \mathrm{~h}$ ) and in water $(3 \mathrm{~L}$ at 1300 and 2200 h). Calves had no supplemental access to plain water. Blood samples were taken at $0600 \mathrm{~h}$ for $4 \mathrm{~d}$, and fecal scores ( $0=$ normal; $1=$ watery feces) were assessed daily at $0900 \mathrm{~h}$ for 15 consecutive days. Additionally, skin turgor and degree of enophthalmos were assessed at $1000 \mathrm{~h}$ from d 1 to 4 using a 3-level scoring system. Calves fed OES had a higher prevalence of diarrhea on

Received July 31, 2019.

Accepted January 7, 2020.

*Corresponding author: juliette.wilms@trouwnutrition.com $\mathrm{d} 3,4$, and 5 as well as higher prevalence of delayed skin turgor and increased degree of enophthalmos over the 4 monitoring days. Diarrhea duration was longer in calves receiving OES than in calves receiving CON (4.2 d vs. $2.1 \mathrm{~d}$, respectively). The OES treatment resulted in hypernatremia (serum $\mathrm{Na}^{+}>145 \mathrm{mmol} / \mathrm{L}$ ) within 48 $\mathrm{h}$ after the first OES administration. Hypernatremia was linked with higher serum $\mathrm{Cl}^{-}$and urea concentrations and thus higher serum osmolarity in OES calves compared with CON calves. Administered under these conditions, OES resulted in various degrees of hypernatremia and a delayed recovery from diarrhea, thus defeating the purpose of OES administration.

Key words: hypernatremia, calf diarrhea, oral electrolyte solution

\section{Short Communication}

Oral rehydration therapy was originally developed in human medicine in the 1960s for diarrhea treatment associated with cholera infection and allows for the prevention of more than 1 million deaths per year (Mota-Hernández and Morales-Barradas, 1990). Oral electrolyte solutions (OES) became part of the standard treatment protocol for diarrheic calves (Smith and Berchtold, 2014), and the use of OES is a wellaccepted lifesaving measure (Pringle and Berthiaume, 1988). However, considerable variability exists in the composition and the administration protocols of OES for calves. Thus, it is not safe to assume that all OES administration protocols for calves are similarly effective in mitigating dehydration and metabolic acidosis.

The World Health Organization has set recommendations regarding OES for rehydration therapy in humans. Solutions should have an osmolality of 245 $\mathrm{mOsm} / \mathrm{kg}$ in water, including $75 \mathrm{mmol} / \mathrm{L}$ sodium $\left(\mathrm{Na}^{+}\right)$ and $75 \mathrm{mmol} / \mathrm{L}$ dextrose. In contrast, commercially available OES for calves usually contain higher $\mathrm{Na}^{+}$ concentrations (>90 mmol/L) and higher dextrose concentrations $(>100 \mathrm{mmol} / \mathrm{L})$. Administration of sugar and mineral mix in whole milk (WM) or milk replacer (MR) has become a common practice in past decades 
because it allows a substantial reduction of labor associated with the treatment of diarrheic calves (Bachmann et al., 2012). However, one should consider that WM and especially MR already contain high amounts of lactose $(140-230 \mathrm{mmol} / \mathrm{L})$ and $\mathrm{Na}^{+}(17-80 \mathrm{mmol} / \mathrm{L}$; Byers et al., 2014). The high $\mathrm{Na}^{+}$concentrations in $\mathrm{MR}$ are due to the high $\mathrm{Na}^{+}$content of whey (up to $2 \%$ ) used to formulate MR (Byers et al., 2014) and the high percentage of solids per liter of solution in MR (up to $20 \%$ ). Therefore, mixing sugar and mineral powder into WM or MR likely increases the osmolality of the solution above $600 \mathrm{mOsm} / \mathrm{kg}$.

Access to water is compulsory when sugar and mineral mix is added to WM or MR to allow for renal excretion of the $\mathrm{Na}^{+}$and $\mathrm{Cl}^{-}$overload that accumulates into the extracellular fluid space (Byers et al., 2014). However, access to water for calves younger than $4 \mathrm{wk}$ of age is not always available on veal and dairy farms. Dairy producers wait for $17 \mathrm{~d}$ on average to first offer drinking water to newborn calves (USDA, 2016). This delay in offering drinking water may be the result of an effort to save labor or the unfounded belief that water induces diarrhea and reduces milk intake (Beede, 2005; Kertz et al., 2017). Water requirements are not emphasized on the labels of commercially available OES products. As a result, the risks associated with administration of OES are not always understood and are often underestimated by producers. The administration of sugar and mineral powder mix in WM and MR therefore may compromise calf health. In this light, the objective of the current study was to expose the risks associated with the administration of sugar and mineral powder simultaneously in MR and water in absence of water access in male Holstein calves with naturally occurring diarrhea.

The study was carried out at a commercial veal farm (Winssen, the Netherlands) between November and December 2014. Male Holstein-Friesian calves with naturally occurring diarrhea were used in a randomized block design. Forty-five calves $(16.6 \pm 1.6 \mathrm{~d}$ of age and $45.4 \pm 2.2 \mathrm{~kg}$ at arrival) were acquired from a collection center (Pali Group, 's-Hertogenbosch, the Netherlands). Calves were housed indoors in individual pens separated by wooden fences and equipped with wooden slatted floors. After arrival, calves went through an adaptation period of $4 \mathrm{~d}$. Calves developing diarrhea within $6 \mathrm{~d}$ after the end of the adaptation period were enrolled in the study, and the remaining calves were sold after being weaned. Diarrhea was assessed upon morning detection of abnormal fecal scores. The first day on which diarrhea was observed was considered d 1 (starting point) of 4 consecutive days of treatment administration. Calves were blocked based on BW measured at arrival, and within each block calves were ran- domly assigned to 1 of 2 treatments, including an OES treatment $(\mathrm{n}=14)$ and a control treatment $(\mathbf{C O N}, \mathrm{n}$ =12), by the lead researcher using an Excel (Microsoft Corp., Redmond, WA) spreadsheet. Treatments were blinded to the farm staff by randomly assigning a letter to each treatment. All of the personnel involved in the execution of the experiment with the exception of the lead researcher were led to believe that the experiment was comparing the efficacy of 2 OES treatments. Calves with dehydration greater than $8 \%$ of BW (Smith and Berchtold, 2014) were excluded from the study and provided with intravenous saline infusion and additional appropriate medical care.

Calves received 1 of 2 treatments, including a sugar and mineral mix (OES) or a control (CON) consisting of a low dose of whey powder. Whey powder was chosen as the placebo under the assumption that at a low dose $(5 \mathrm{~g} / \mathrm{L})$, it would represent an innocuous intervention. Composition of treatments in MR and water is presented in Table 1. Treatments were administered for 4 consecutive days simultaneously in MR $(2.5 \mathrm{~L}$ at 0800 and $1730 \mathrm{~h}$ ) and in water (3 L at 1300 and 2200 h). Calves had no supplemental access to plain water. This feeding scheme was based on growing commercial practices observed in the field. The concentration of the OES treatment was $50 \mathrm{~g} / \mathrm{L}$ of water and $25 \mathrm{~g} / \mathrm{L}$ of MR. The concentration of whey powder in the CON treatment was $5 \mathrm{~g} / \mathrm{L}$ of water and of MR. Milk replacer was reconstituted with water at a concentration of 150 $\mathrm{g} / \mathrm{L}$ and supplied in a teat bucket at $40^{\circ} \mathrm{C}$. Calves were offered $2.5 \mathrm{~L}$ of MR twice daily at 0800 and $1730 \mathrm{~h}$. Calves were allowed to consume MR for $15 \mathrm{~min}$ and the water-based OES for $1 \mathrm{~h}$. Treatments were never drenched to evaluate voluntary consumption. At the end of the $4 \mathrm{~d}$ of treatment administration, water was resumed and solid feed was provided. Body weights were measured on the day of arrival. Intakes of treatments (milk-based and water-based) were recorded throughout the study period by weighing leftovers. Blood samples were taken via the jugular vein from $\mathrm{d} 1$ to 4 at $0600 \mathrm{~h}$, and fecal scores $(0=$ normal; $1=$ watery feces) were assessed from d 1 to 15 at $0900 \mathrm{~h}$. The degree of dehydration was assessed by evaluating the skin turgor and the degree of dehydration at $1000 \mathrm{~h}$ from $\mathrm{d} 1$ until d 4. Skin turgor was scored by measuring the time needed for the skin of the eyelids to go back to normal after being pinched (0: immediately; $1: 2-4 \mathrm{~s} ; 2: \geq 5 \mathrm{~s}$ ). The degree of enophthalmos was assessed by looking at the position of the eyeball in the eye socket $(0:<2 \mathrm{~mm}$; 1: eyeball moderately sunken, visible gap $2-4 \mathrm{~mm} ; 2$ : eyeball severely sunken, visible gap $\geq 5 \mathrm{~mm}$ ).

Blood samples were processed and analyzed at the Animal Health Service (Gezondheidsdienst voor Dieren, Deventer, the Netherlands). Serum macrominer- 
Table 1. Descriptive summary of milk replacer and treatment components for calves with naturally occurring diarrhea receiving milk-based and water-based electrolyte solutions without access to water $(\mathrm{n}=26)$

\begin{tabular}{|c|c|c|c|c|c|}
\hline \multirow{3}{*}{$\begin{array}{l}\text { Item, mmol/L unless } \\
\text { otherwise noted }\end{array}$} & \multirow{3}{*}{$\begin{array}{l}\text { Milk } \\
\text { replacer }\end{array}$} & \multicolumn{4}{|c|}{ Treatment $^{1}$} \\
\hline & & \multicolumn{2}{|c|}{ Water-based } & \multicolumn{2}{|c|}{ Milk-based } \\
\hline & & $\mathrm{CON}$ & OES & $\mathrm{CON}$ & OES \\
\hline \multicolumn{6}{|l|}{ Carbohydrates } \\
\hline Lactose & 202 & 10 & 0 & 212 & 202 \\
\hline Dextrose & 21 & 0 & 187 & 21 & 115 \\
\hline \multicolumn{6}{|l|}{ Macrominerals } \\
\hline $\mathrm{Na}^{+}$ & 48 & 2 & 119 & 50 & 108 \\
\hline $\mathrm{K}^{-}$ & 71 & 3 & 10 & 74 & 77 \\
\hline $\mathrm{Cl}^{-}$ & 61 & 2 & 77 & 63 & 99 \\
\hline \multicolumn{6}{|l|}{ Alkalinizing agent } \\
\hline Bicarbonate & 0 & 0 & 42 & 0 & 21 \\
\hline $\mathrm{SID},{ }^{2} \mathrm{mEq} / \mathrm{L}$ & 59 & 2 & 53 & 61 & 85 \\
\hline Osmolality, ${ }^{3} \mathrm{mOsm} / \mathrm{kg}$ & 459 & 17 & 504 & 476 & 704 \\
\hline
\end{tabular}

${ }^{1}$ Treatments were administered for 4 consecutive days simultaneously in milk replacer $(2.5 \mathrm{~L}$ at 0800 and 1730 h) and water ( $3 \mathrm{~L}$ at 1300 and $2200 \mathrm{~h}$ ). Besides administration of treatments, calves had no supplemental access to water. Concentration of treatments in water was $5 \mathrm{~g} / \mathrm{L}$ for the control $(\mathrm{CON})$ group and $50 \mathrm{~g} / \mathrm{L}$ for the oral electrolyte solution (OES) group. Concentration of treatments in milk replacer was $5 \mathrm{~g} / \mathrm{L}$ for $\mathrm{CON}$ and $25 \mathrm{~g} / \mathrm{L}$ for OES.

${ }^{2}$ The strong ion difference (SID) of the solutions was calculated as $\mathrm{SID}(\mathrm{mEq} / \mathrm{L})=\left(\mathrm{Na}^{+}+\mathrm{K}^{+}\right)-\mathrm{Cl}^{-}$.

${ }^{3}$ Osmolality (in mol $/ \mathrm{kg}$ of solvent and expressed in $\mathrm{mOsm} / \mathrm{kg}$ ) was calculated by adding by adding concentrations of carbohydrates, macrominerals, and bicarbonate.

als were analyzed by inductively coupled plasma MS using a Synchron Chemistry Analyzer (UniCel DxC 600 SN6730, Beckman Coulter, Brea, CA). Total serum protein, glucose, urea, and creatinine were analyzed using a Synchron Clinical Analyzer (Unicel DxC 800 SN4764, Beckman Coulter). Hematocrit in whole blood was analyzed using a Cell-DYN Hematology Analyzer (Abbott Cell-DYN 3700 SN22072AK, Abbott Core Laboratory, Abbott Park, IL). All standards were performed according to ISO (2017).

The study was dimensioned to detect differences in serum $\mathrm{Na}^{+}$concentrations, treated as a continuous variable. The power $(1-\beta)$ was chosen to be equal to $80 \%$, and the $\alpha$-level was 0.05 . Based on the outcome of a previously conducted experiment at the Calf Research Facility of Trouw Nutrition Research and Development (Winssen, the Netherlands; J. Wilms, Trouw Nutrition R\&D, unpublished data) investigating OES efficacy for 15 calves per treatment group (including a control or an OES group) on d 4 of diarrhea, a standard deviation of $4.2 \mathrm{mmol} / \mathrm{L}$ was assumed for serum $\mathrm{Na}^{+}$. The minimal meaningful difference was considered to be 4.5 $\mathrm{mmol} / \mathrm{L}$. The minimal sample size to detect differences would then be 14 calves per treatment group. Continuous variables were analyzed using mixed model analysis with PROC MIXED of SAS (SAS 9.4M6, SAS Studio, SAS Institute Inc., Cary, NC). Calf was considered the experimental unit. The model included the fixed effects of block, treatment, time, and the interaction between treatment and time. Time entered the model as a re- peated statement. Blood parameters measured on d 1 , before treatment administration, entered the model as baseline covariate. The heterogeneous autoregressive covariance structure was applied to all analyzed blood variables. The analysis of diarrhea prevalence and dehydration parameters was conducted with PROC GENMOD of SAS (SAS 9.4M6, SAS Studio, SAS Institute Inc.). Significant interactions of treatment by time were explored using the SLICE option of the LSMEANS statement of PROC MIXED of SAS. Comparisons across treatments at each significant time point were conducted with the PDIFF option of the LSMEANS statement of SAS. Variables were declared significant at $P \leq 0.05$ and trends were reported when $P<0.10$.

The study was based on naturally occurring diarrhea to reflect conventional rearing practices. Two calves in the CON group were not correctly diagnosed at the start and recovered on the same day as the treatment allocation; these 2 animals were removed after inclusion. As a result, the OES treatment included 14 calves, whereas the CON treatment included 12 calves. The time elapsed between arrival at the farm and inclusion in the study was $5 \pm 2 \mathrm{~d}$. Parameters measured on $\mathrm{d}$ 1 , before administration of treatments, did not differ across treatment groups. Calves voluntarily consumed treatments when administered in $\mathrm{MR}(4.9 \mathrm{~L} / \mathrm{d})$ and in water $(4.6 \mathrm{~L} / \mathrm{d})$, and intakes did not differ across treatment groups. Prevalence of diarrhea was higher in calves receiving OES on d 3,4 , and 5 compared with 
CON calves (Figure 1). Additionally, diarrhea duration was longer in calves receiving OES than in CON calves (4.2 d vs. $2.1 \mathrm{~d}$, respectively; $P<0.01$ ). Concentrations of $\mathrm{Na}^{+}$and dextrose in the OES treatment were higher than $100 \mathrm{mmol} / \mathrm{L}$ in both water and MR. As a consequence, osmolality of the OES treatment was $504 \mathrm{mOsm} / \mathrm{kg}$ in water and $704 \mathrm{mOsm} / \mathrm{kg}$ in MR. The excess of solutes present in these hypertonic solutions may have resulted in osmotic diarrhea, thus further pulling water into the lumen of the gut and further stimulating gastrointestinal mucosal damages (Byers et al., 2014; Wilms et al., 2019). These results suggest that providing sugar and mineral powder mix in MR without access to water delays recovery from diarrhea.

In addition to longer diarrhea duration, calves in the OES group displayed clinical signs of dehydration as shown by higher scores for both skin turgor and degree of enophthalmos. Over the 4 monitoring days, $25 \%$ of calves receiving OES had delayed skin turgor $(\geq 2 \mathrm{~s})$ compared with only $9 \%$ in the CON group $(P=0.04)$. Similarly, $23 \%$ of calves receiving OES had a visible gap ( $\geq 2 \mathrm{~mm}$ ) between eyeball and eye socket compared with only $6 \%$ in the CON group $(P=0.02)$. According to Dillane et al. (2018), the normal reference range for serum $\mathrm{Na}^{+}$for male calves of 11 to $30 \mathrm{~d}$ of age is between 134.2 and $139.3 \mathrm{mmol} / \mathrm{L}$. Serum $\mathrm{Na}^{+}$of calves receiving the OES treatment was higher than the normal upper limit (up to $169 \mathrm{mmol} / \mathrm{L}$ ). The OES treatment resulted in hypernatremia (serum $\mathrm{Na}^{+}>145 \mathrm{mmol} / \mathrm{L}$; Adrogué and Madias, 2000; Muhsin and Mount, 2016; Verbalis, 2016) within $48 \mathrm{~h}$ after the first administration. There

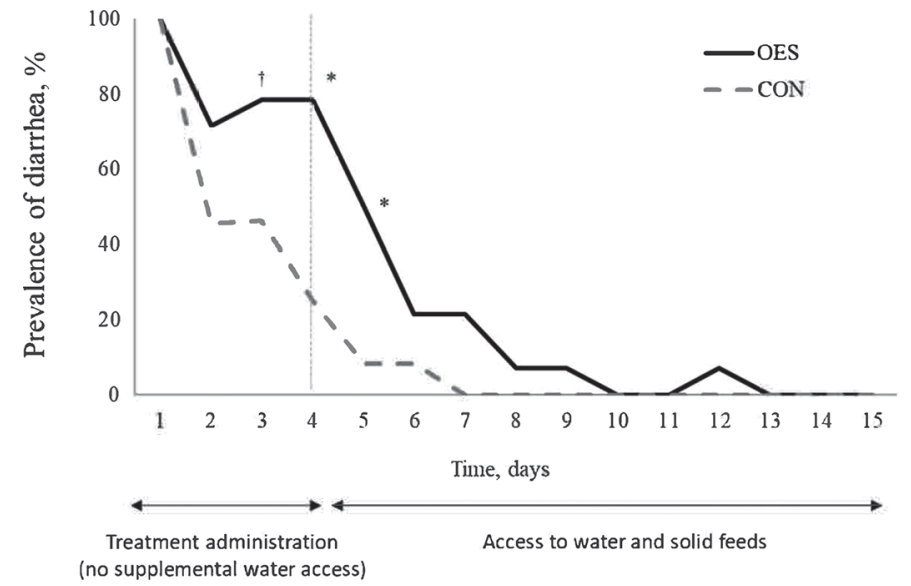

Figure 1. Prevalence of diarrhea in calves fed a control (CON, n $=12)$ or an oral electrolyte solution (OES, $\mathrm{n}=14$ ) applied in water and in milk replacer without access to water. Significant treatment $\times$ time differences at each time point are indicated by $*(P \leq 0.05)$ and $\dagger(P<0.10)$.

was a significant treatment by time interaction for serum $\mathrm{Na}^{+}$, describing the increase of serum $\mathrm{Na}^{+}$through time for calves receiving OES (149 mmol/L) compared with CON calves (137 mmol/L; Table 2; Figure 2A). Similarly, serum $\mathrm{Cl}^{-}$was higher in calves fed OES (114 $\mathrm{mmol} / \mathrm{L})$ than in CON calves $(102 \mathrm{mmol} / \mathrm{L})$. Incidence of hypernatremia over the 4 sampling days was $71 \%$ $(10 / 14)$ in calves fed OES. Incidence of acute hypernatremia, defined as hypernatremia developing within $48 \mathrm{~h}$ and with serum $\mathrm{Na}^{+}$concentrations above 160 mmol/L (Byers et al., 2014), was 21\% (3/14). This

Table 2. The effect of oral administration of milk-based and water-based electrolyte solutions without access to water on blood minerals, blood hematology, and blood chemistry, measured at $0600 \mathrm{~h}$ from d 1 to 4 , in calves with naturally occurring diarrhea $(\mathrm{n}=26)$

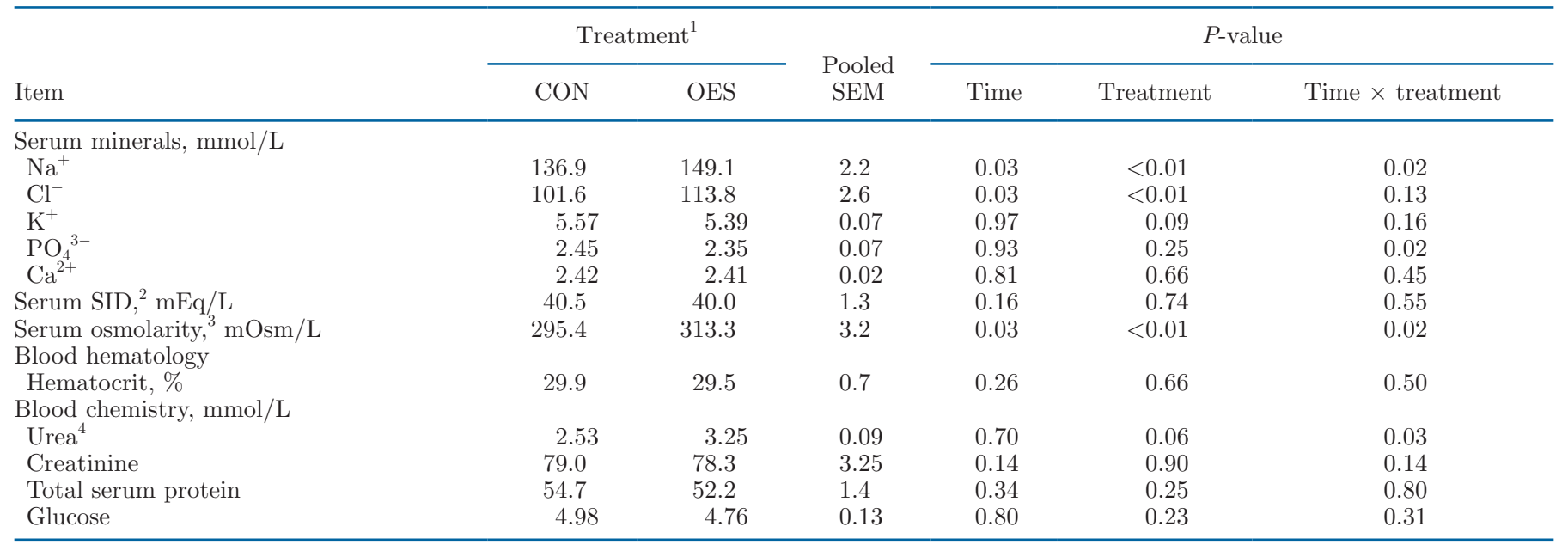

${ }^{1} \mathrm{CON}=$ control $(\mathrm{n}=12) ;$ OES $=$ oral electrolyte solution $(\mathrm{n}=14)$.

${ }^{2}$ The serum strong ion difference (SID) was calculated as $\mathrm{SID}(\mathrm{mEq} / \mathrm{L})=\left(\mathrm{Na}^{+}+\mathrm{K}^{+}\right)-\mathrm{Cl}^{-}$.

${ }^{3}$ Calculated as serum osmolarity $(\mathrm{mOsm} / \mathrm{L})=2 \mathrm{Na}^{+}+2 \mathrm{~K}^{+}+$glucose + urea.

${ }^{4}$ Expressed as log SEM. 
was the consequence of excessive amounts of $\mathrm{Na}^{+}$and $\mathrm{Cl}^{-}$that were added to the extracellular space without the adequate amount of water (Byers et al., 2014). As free water was not available, OES calves were unable to restore their normal serum $\mathrm{Na}^{+}$concentrations by increasing $\mathrm{Na}^{+}$renal excretion. According to Koch and Fulop (2017), hypernatremia is corrected by calculating the free water deficit as followed: $4 \mathrm{~mL} \times \mathrm{BW} \times($ desired change in serum $\mathrm{Na}^{+}$, expressed in mmol/L). This means that for a $45-\mathrm{kg}$ calf with serum $\mathrm{Na}^{+}$concentrations of $160 \mathrm{mmol} / \mathrm{L}$, the free water deficit needed to normalize serum $\mathrm{Na}^{+}$concentrations to $140 \mathrm{mmol} / \mathrm{L}$ was about $3.7 \mathrm{~L}$.

There was also a significant treatment by time interaction for serum urea $(P=0.01)$, which was translated in higher serum urea concentrations on $\mathrm{d} 3$ and 4 in calves receiving the OES treatment (Figure 2B). Serum urea reflects the balance between urea production and urea elimination in urine (Higgins, 2016). In the current study, the gradual increase in serum urea concentrations was likely due to lower urea excretion by the kidney due to the lack of water intake. However, hematocrit, which represents the amount of red blood cells in blood and which is an indicator of the hydration status of the animals, did not differ across treatment groups. This increase in the concentrations of blood metabolites (sodium, chloride, and urea) resulted in higher serum osmolarity in calves fed OES (313 mOsm/L) compared with CON calves (295 mOsm/L; Table 2; Figure 2C). Serum osmolarity is regulated within narrow ranges (275-295 mOsm/L) in healthy individuals, and even slight elevations in osmolarity lead to the secretion of antidiuretic hormone, which is the main hormone responsible for tonicity homeostasis. Hyperosmolar states trigger its release. According to Davies (1972), osmoreceptors present in the hypothalamus and responsible for antidiuretic hormone release respond to changes in serum osmolarity as little as 2 $\mathrm{mOsm} / \mathrm{L}$. A few animals (3/14) in the OES group had values equal to or greater than $350 \mathrm{mOsm} / \mathrm{L}$, which represents a variation of about $50 \mathrm{mmol} / \mathrm{L}$ in serum osmolarity and can therefore be considered acute serum hyperosmolarity. Thus, calves in the OES group likely experienced an intense feeling of thirst (Adrogué and Madias, 2000). The significant treatment by time interaction for serum osmolarity was associated with a gradual increase in hypernatremia severity through time. Thus, as serum osmolarity increased, the health status of the animals steadily declined. As calves in the CON group recovered from diarrhea $2 \mathrm{~d}$ earlier than calves in the OES group, it can be considered that the harm of such feeding protocols primarily comes from the hypernatremia and the hyperosmolar state rather than from the lack of correction of dehydration.
This study demonstrated that administration of OES in milk without access to water delays recovery from diarrhea and results in various degrees of hypernatremia. Therefore, oral electrolyte solutions with $\mathrm{Na}^{+}$concentrations greater than $130 \mathrm{mmol} / \mathrm{L}$ and osmolality greater than $400 \mathrm{mOsm} / \mathrm{kg}$ should be offered to calves with caution. Ideally, OES should be offered separately in addition to usual milk provisions while maintaining ad libitum access to water (Smith, 2009). The use of OES mixed into milk therefore represents a practice that can compromise the health and welfare of calves when water is not available.
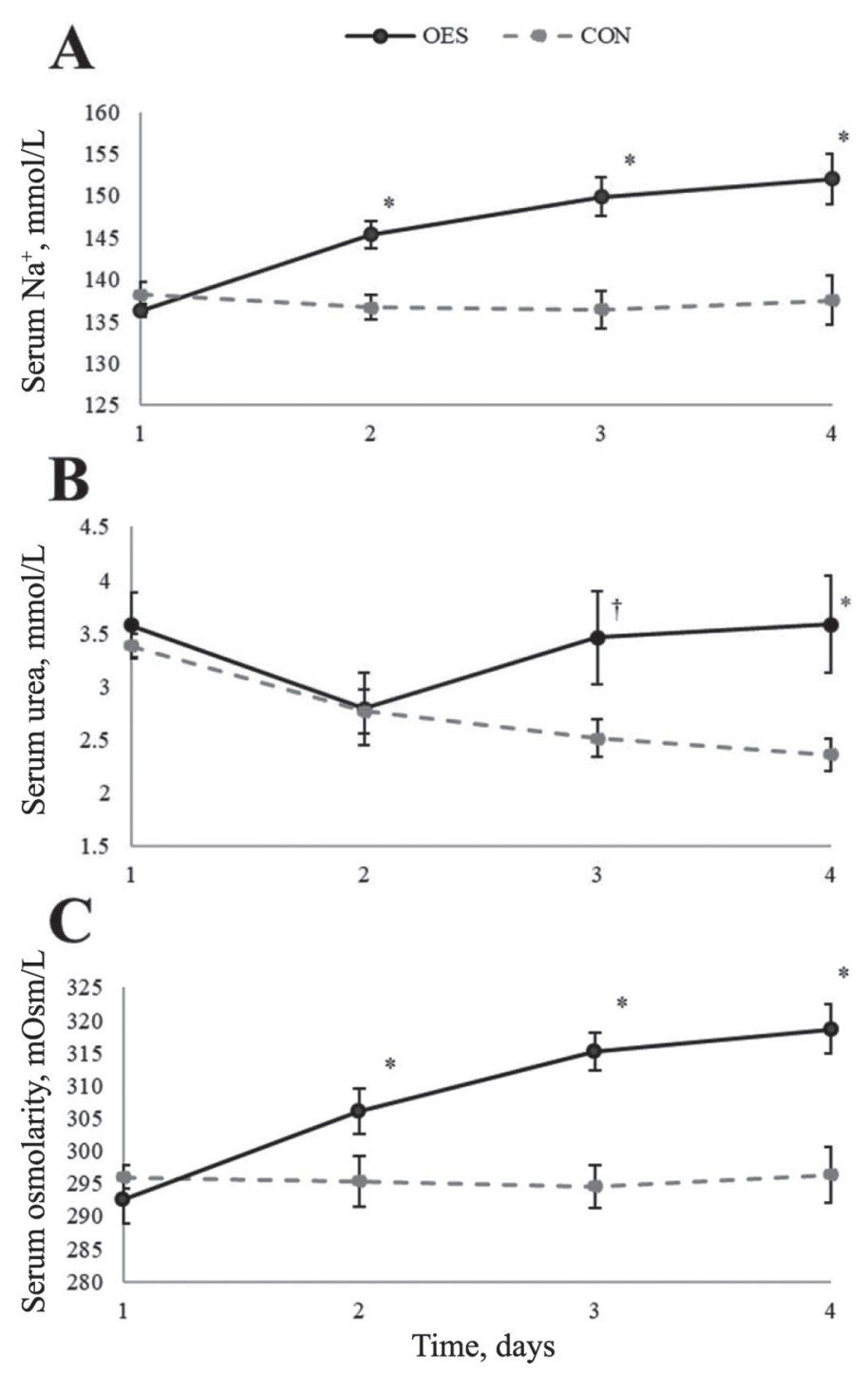

Figure 2. (A) Serum sodium, (B) serum urea, and (C) serum osmolarity measured at $0600 \mathrm{~h}$ from $\mathrm{d} 1$ to 4 in diarrheic calves receiving a control $(\mathrm{CON}, \mathrm{n}=12)$ or an oral electrolyte solution (OES, $\mathrm{n}=14)$ administered in water and in milk replacer without access to water. Significant treatment $\times$ time differences at each time point are indicated by $*(P \leq 0.05)$ and $\dagger(P<0.10)$. 


\section{ACKNOWLEDGMENTS}

The authors thank the personnel of the Calf Research Facility of Trouw Nutrition (Winssen, the Netherlands) for their technical assistance. The present study was funded by Trouw Nutrition (Amersfoort, the Netherlands), a company with commercial interests in oral electrolyte solutions. The authors have not stated any other conflicts of interest.

\section{REFERENCES}

Adrogué, H. J., and N. E. Madias. 2000. Hypernartemia. N. Engl. J. Med. 342:1493-1499. https://doi.org/10.1056/NEJM200005183422006.

Bachmann, L., B. Schmidt, U. Rauwolf, J. Wenge, and M. Coenen 2012. Change of plasma volume, osmolality, and acid-base status in healthy calves after feeding of milk and water- and milk-based oral rehydration solutions. J. Dairy Sci. 95:6006-6014. https://doi .org/10.3168/jds.2012-5562.

Beede, D. K. 2005. The most essential nutrient: Water. Pages 1332 in Proc. 7th Western Dairy Management Conference, Reno, NV. http://www.msu.edu/ beede/Water_MostEssentialNutrient _Beede_Mar20051.pdf.

Byers, S. R., A. S. Lear, and D. C. Van Metre. 2014. Sodium balance and the dysnatremias. Vet. Clin. North Am. Food Anim. Pract. 30:333-350. https://doi.org/10.1016/j.cvfa.2014.03.003.

Davies, A. G. 1972. Antidiuretic and growth hormones. BMJ 2:282284. https://doi.org/10.1136/bmj.2.5808.282.

Dillane, P., L. Krump, A. Kennedy, R. G. Sayers, and G. P. Sayers 2018. Establishing blood gas ranges in healthy bovine neonates differentiated by age, sex, and breed type. J. Dairy Sci. 101:32053212. https://doi.org/10.3168/jds.2017-13445.

Higgins, C. 2016. Urea and creatinine concentration, the urea: creatinine ratio. Accessed October 2016. https://acutecaretesting .org/-/media/acutecaretesting/files/pdf/urea-and-creatinine -concentration-the-ureacreatinine-ratio.pdf.

ISO (International Organization for Standardization). 2017. ISO/IEC 17025. General requirements for the competence of testing and calibration laboratories. ISO, Geneva, Switzerland.
Kertz, A. F., T. M. Hill, J. D. Quigley III, A. J. Heinrichs, J. G. Linn, and J. K. Drackley. 2017. A 100-year review: Calf nutrition and management. J. Dairy Sci. 100:10151-10172. https://doi.org/10 .3168/jds.2017-13062.

Koch, C. A., and T. Fulop. 2017. Clinical aspects of changes in water and sodium homeostasis in the elderly. Rev. Endocr. Metab. Disord. 18:49-66. https://doi.org/10.1007/s11154-017-9420-5.

Mota-Hernández, F., and J. A. Morales-Barradas. 1990. Sodium concentrations in solutions for oral rehydration in children with diarrhea. Bol. Med. Hosp. Infant Mex. 47:285-291.

Muhsin, S. A., and D. B. Mount. 2016. Diagnosis and treatment of hypernatremia. Best Pract. Res. Clin. Endocrinol. Metab. 30:189 203. https://doi.org/10.1016/j.beem.2016.02.014.

Pringle, J. K., and L. M. M. Berthiaume. 1988. Hypernatremia in calves. J. Vet. Intern. Med. 2:66-70. https://doi.org/10.1111/j .1939-1676.1988.tb02795.x.

Smith, G. W. 2009. Treatment of calf diarrhea: Oral fluid therapy. Vet. Clin. North Am. Food Anim. Pract. 25:55-72. https://doi.org/10 .1016/j.cvfa.2008.10.006.

Smith, G. W.. and J. Berchtold. 2014. Fluid therapy in calves. Vet. Clin. North Am. Food Anim. Pract. 30:409-427.

USDA. 2016. Dairy 2014: Dairy cattle management practices in the United States. Pages 120-140 in National Animal Health Monitoring Systems. Section I: Population estimates-C. Preweaned heifer management. USDA, Washington, DC.

Verbalis, J. G. 2016. Disorders of water balance. Pages 101-131 in Brenner and Rector's The Kidney. Elsevier Health Sciences Division, Amsterdam, the Netherlands.

Wilms, J., H. Berends, and J. Martín-Tereso. 2019. Hypertonic milk replacers increase gastrointestinal permeability in healthy dairy calves. J. Dairy Sci. 102:1237-1246. https://doi.org/10.3168/jds .2018-15265.

\section{ORCIDS}

Juliette N. Wilms @ (ㄴ) https://orcid.org/0000-0003-1725-1087

Leonel N. Leal @ https://orcid.org/0000-0002-7798-3995

Javier Martín-Tereso @ https://orcid.org/0000-0002-6757-4629 